\title{
Numalata / Namalta (Tribu)
}

\section{Abderrahmane Khelifa}

\section{OpenEdition}

Journals

Édition électronique

URL : https://journals.openedition.org/encyclopedieberbere/2767

DOI : 10.4000/encyclopedieberbere. 2767

ISSN : 2262-7197

\section{Éditeur}

Peeters Publishers

\section{Édition imprimée}

Date de publication : 5 octobre 2012

Pagination : 5632

ISBN : 978-90-429-2718-6

ISSN : 1015-7344

\section{Référence électronique}

Abderrahmane Khelifa, « Numalata / Namalta (Tribu) », Encyclopédie berbère [En ligne], 34 | 2012

document N75, mis en ligne le 15 décembre 2020, consulté le 17 février 2022. URL : http://

journals.openedition.org/encyclopedieberbere/2767; DOI : https://doi.org/10.4000/

encyclopedieberbere. 2767

Ce document a été généré automatiquement le 17 février 2022.

(c) Tous droits réservés 


\section{Numalata / Namalta (Tribu)}

\section{Abderrahmane Khelifa}

1 Selon Ibn Hazm, Ibn Khaldoûn et les généalogistes berbères zénatiens, Djana aurait eu plusieurs enfants dont Ferini. Celui-ci eut à son tour plusieurs enfants dont Numalata, Izmerten, Mendjaça, Ouergla et Sebertera.

2 El-Bekrî compte les Numalata parmi les tribus musulmanes orthodoxes (Zenata de la montagne, les Béni Ilit, les Béni Ouaoucint, les Béni Ifren*, les Béni Ifellouça, les Béni Isker...) rattachées à l'empire des Barghawata*. La ville de Numalata apparaît à l'époque d'Idrîs II. Elle aurait été fondée sur le site de Numerus Syrorum (Maghnia). El-Idrîssî, décrivant la route de Fès à Tlemcen passant par le Sebou, affirme que la route passe par Namalita, qui est un village entouré de terres de culture et arrosé par un cours d'eau qui lui vient du sud, appelé Ouadi Inawan ${ }^{1}$. Cette ville est à une étape de Fès. Il semble qu'El-Idrîssî situe la ville beaucoup plus à l'ouest que Maghnia. Cette tribu a-t-elle connu un glissement à l'ouest au XII ${ }^{\mathrm{e}}$ siècle alors qu'à l'époque de Ya'qubî (IX ${ }^{\mathrm{e}}$ siècle) elle était située dans la zone des Traras*?

\section{BIBLIOGRAPHIE}

EL-BEKRÎ, Description de l'Afrique septentrionale, traduction de Slane, Paris, Geuthner, 1965.

EL-IDRÎSSî, Le Maghreb au XII siècle, (VI ${ }^{e}$ siècle de l'Hégire), texte établi et traduit d'après Nuzhât ElMushtâq par M. Hadj Sadok, Alger, OPU, 1983.

IBN KHALDOÛN A., Histoire des Berbères et des dynasties septentrionales de l'Afrique du nord, 4 tomes, traduction de Slane, Paris, Geuthner, 1978.

POTIRON G., Tribus (Liste des tribus berbères), Mémoire de DES, Université d'Alger, 1956. 


\section{NOTES}

1. On notera qu'il existe une tribu des Inawen sur l'histoire de laquelle on peut trouver des données importantes dans une excellente thèse publiée à Rabat: Abderrahman El Moudden: Bawâdî (al-) al-maghribiyya qabla l-isti'mâr. Qabâ'il Inawen wa l-makhzan bayna l-qarn alsâdis'acar wa ttâsi' acar [Les campagnes marocaines avant la colonisation. Les tribus Inawen et le Makhzen $d u 16^{e}$ au $19^{e}$ siècle], Faculté des lettres et des sciences humaines, Université Mohamed V, 1995, p. 50-132. NDLR.

\section{INDEX}

Mots-clés : Algérie, Moyen Âge, Tribu 